\title{
Formação de professores em Educação Especial: Um estudo de educação comparada entre Brasil e Portugal
}

\section{Teacher training in Special Education: A comparative study between Brazil and Portugal}

\author{
Edith Romano*, Jorge Bonito** \\ * CEDUC da Universidade Federal de Roraima, Brasil ** Universidade de Évora. CIDTFF da Universidade de Aveiro, Portugal
}

\begin{abstract}
Resumo
Este trabalho apresenta um estudo comparativo entre Brasil e Portugal acerca da formação de professores para a educação especial. Desenvolvido na perspetiva de educação comparada em abordagem sócio-histórica, apresenta resultados decorrentes da análise documental e de entrevistas. Aponta diferenças relevantes na perceção quanto aos sentidos atribuídos à inclusão, que determinam: a quantidade e qualidade dos apoios especializados disponibilizados ao público-alvo da educação especial; as relações dos professores do ensino regular com os seus alunos; e a forma como os professores de educação especial se articulam com os seus colegas do ensino regular nos ambientes escolares dos dois países.

Palavras chave: necessidades educativas especiais, formação de professores, educação especial.
\end{abstract}

\begin{abstract}
This paper presents a comparative study between Brazil and Portugal about teacher education for special education. Developed from the perspective of comparative education in socio-historical approach, it presents results from documentary analysis and interviews. It points out relevant differences in the perception regarding the meanings attributed to inclusion, which determine: the quantity and quality of the specialized supports made available to the target audience of special education; the relationships of regular teachers with their students; and the way special education teachers articulate with their regular teaching colleagues in the school settings of the two countries.

Keywords: special educational needs, teacher training, special education.
\end{abstract}

\section{Introdução}

Garantir às pessoas com necessidades educativas especiais (NEE) o acesso ao conhecimento socialmente acumulado e à convivência social em espaços escolares em que se encontrem efetivamente incluídas é um desafio que se coloca na contemporaneidade para diferentes sociedades. Considera-se fundamental, para que a educação escolar em contexto inclusivo se efetive, a formação de professores do ensino regular e de educação especial aptos a construir estratégias pedagógicas que viabilizem que este processo ocorra com sucesso, aqui entendido o sucesso como a efetiva participação social dos estudantes e apropriação dos saberes estabelecidos no currículo.

Este trabalho objetiva apresentar um estudo comparativo entre Brasil e Portugal acerca do modo como estes países enfrentam o desafio de formar professores de educação especial numa perspetiva inclusiva, destacando-se as semelhanças e diferenças nos caminhos adotados, não apenas no plano normativo e legal mas também no plano da formação que vem sendo vivenciado, em especial no caso português, por docentes da educação especial e formadores de professores. Desenvolvido na perspetiva de educação comparada em abordagem sócio-histórica, apresentamos um percurso de pesquisa que partiu de análise do ordenamento legal da área nos dois países, passou pela aproximação com as práticas escolares de educação de estudantes com NEE em perspetiva inclusiva, finalizando com a análise dos processos de formação de professores, através de entrevistas com docentes de disciplinas que tem por objeto as necessidades educativas especiais, e coordenadores de cursos de mestrado em educação especial de instituições portuguesas, dando destaque aos sentidos atribuídos por estes sujeitos à qualidade desta formação.

É possível identificar, como elemento central, que existem diferenças relevantes na perceção quanto ao conceito de inclusão dos alunos com NEE nos dois países. Estes diferentes sentidos atribuídos à inclusão acabam por serem determinantes em três eixos de análise: a quantidade e qualidade dos apoios especializados oferecidos ao público-alvo da educação especial; as relações dos professores do ensino regular com os seus alunos; e a forma como os professores de educação especial se articulam com os seus colegas do ensino regular nos ambientes escolares dos dois países.

\section{Formação de professores em NEE}

Acompanhando os movimentos mundiais de reconhecimento de direitos das pessoas com deficiência, a legislação federal brasileira e a legislação portuguesa, das décadas de 1980-1990, incluem o direito à educação das pessoas que passam a ser concebidas como tendo 
"necessidades educativas especiais", conforme conceito estabelecido no Relatório Warnock de 1975.

$\mathrm{Na}$ Constituição Federal brasileira de 1988 existe abundante indicação dos direitos desses cidadãos que se desdobram na Lei de Diretrizes e Bases da Educação brasileira de 1996, num título específico integralmente dedicado ao tema da Educação Especial apontando que os processos educativos devem ocorrer "preferencialmente" no sistema de ensino regular, com referências também às formas de estruturação e de financiamento desses processos. No tocante à formação de professores, esta mesma lei estabelece que os sistemas devem dispor de "professores com especialização adequada em nível médio ou superior, para atendimento especializado, bem como professores do ensino regular capacitados para a integração desses educandos nas classes comuns" (art. 59. ${ }^{\circ}$, inciso III).

Documentos infra legais, como a Resolução do Conselho Nacional de Educação n. ${ }^{\circ} 2$ de 2001, indicam que os sistemas devem contar com professores capacitados, que são aqueles que têm acesso, na sua formação inicial, a conteúdos e saberes do campo da educação especial, e com professores habilitados, que correspondem aos formados em cursos específicos de nível médio ou superior para realizarem o atendimento de estudantes em suas necessidades específicas.

Cumpre ressaltar, ainda nesta Resolução, que se definiu para as escolas a obrigatoriedade de matricular todos os alunos, independentemente de suas condições e, a seguir, encontrar os meios necessários ao adequado atendimento dos estudantes.

$\mathrm{Na}$ efetivação desse processo, num país de dimensões continentais como é o Brasil, conta-se atualmente com um único Programa de Pós-Graduação em Educação Especial e com a oferta de licenciaturas específicas em educação especial em apenas duas universidades: uma localizada na região sul (Universidade Federal de Santa Maria) e outra na região sudeste (Universidade Federal de São Carlos). As possibilidades formativas que atingem um público mais amplo são realizadas em cursos de especialização, oferecidos para finalistas do ensino superior, com duração mínima de 360 horas e que tem uma perspetiva generalista, abordando o amplo espectro das NEE e, na sua maior parte, dispensando a realização de estágios.

Em Portugal, desde 1941, existem registos da existência, em Lisboa, de um curso de formação de professores para a educação especial (Rodrigues \& Nogueira, 2011). Entretanto, a expansão da educação de pessoas com deficiência intensifica-se após a Revolução dos Cravos, em particular em 1979 e é em 1986 que a Lei de Bases do Sistema Educativo (Lei n. ${ }^{\circ}$ 46/86, de 14 de outubro) elege a educação especial como modalidade a consolidar no sistema geral de Educação (arts. 19. ${ }^{\circ}$ al. a), 20..$^{\circ}$ e 21..$^{\circ}$.

Em 2008, duas alterações significativas se apresentam na legislação educacional portuguesa. Em primeiro lugar, o Decreto-Lei n. ${ }^{\circ} 3 / 2008$, de 7 de janeiro, que regulamenta os apoios especializados que deverão ser prestados às crianças na educação pré-escolar e aos alunos dos ensinos básico e secundário dos setores público e particular. Em 2005, na Conferência
Ministerial Europeia sobre o Acordo de Bolonha estabelece-se que a adequação dos ciclos de estudos deve ser realizada até ao final do ano letivo de 2008-2009, prevendo-se que no ano letivo seguinte todos os cursos estejam de acordo com o novo modelo de organização do ensino superior (Decreto-Lei n. ${ }^{\circ}$ 74/2006, de 24 de março).

Desse modo, encontramos na formação de professores uma base geral no primeiro ciclo de estudos (por norma, 180 créditos, i.e., três anos curriculares de trabalho), na qual pode estar presente a oferta de disciplina que faz uma apresentação de aspetos das NEE que todos os professores podem encontrar na escola e que, na maioria dos programas de licenciatura aos quais tivemos acesso, tem duração aproximada de $45 \mathrm{~h}$ de contacto (além das horas de trabalho autónomo) distribuídas entre aulas teóricas e práticas. Após essa etapa os professores, poderão participar em cursos de pós-graduação em áreas específicas, entre elas a da educação especial, com duração de um ou dois anos, consoante se trate, respetivamente, de curso de especialização ou de curso de mestrado.

Existe a possibilidade de professores com pelo menos 5 anos de serviço docente obterem o título de especialista em educação especial, cumprindo dois semestres de atividades teóricas sem a realização de estágios ou pesquisas de campo com estudantes. Esta formação corresponde, em regra, ao primeiro ano do curso de mestrado, não conferindo grau académico mas habilitando para a docência nos grupos de recrutamento 910 (problemas cognitivos, motores, de personalidade e conduta, multideficiência e intervenção precoce na infância), 920 (problemas de surdez e comunicação) e 930 (problemas de cegueira ou baixa visão) da educação

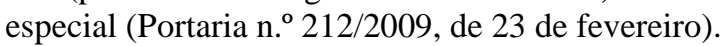

A nível de mestrado, com atribuição de grau académico, a formação é alargada a um domínio específico do desenvolvimento do indivíduo na qual deve constar "uma forte carga de competências práticas e instrumentais indispensáveis ao desempenho profissional" (Costa, 2008), com a realização de uma dissertação.

Ao nível de ações de formação contínua no domínio da educação especial, a deliberação do Conselho Científico-Pedagógico da Formação Contínua (Costa, 2008), definiu que deve ser estruturada contemplando áreas específicas que deverão compor ofertas formativas diferenciadas nos domínios: cognitivo e motor; emocional e da personalidade; audição e surdez; visão; comunicação e linguagem; intervenção precoce na infância.

$\mathrm{O}$ ordenamento jurídico, aqui indicado, incentiva e garante aos cidadãos meios de reivindicarem o acesso aos sistemas de ensino, trazendo desafios para que se possibilite as condições de permanência e de sucesso escolar, aqui entendido como a possibilidade de aquisição do conhecimento social acumulado pelas sociedades. Confronta-se entretanto, com uma tradição de práticas excludentes nas relações sociais e nos espaços de escolarização, a serem superadas. 


\section{Metodologia}

O entendimento dos processos de formação de professores de educação especial no Brasil e em Portugal, demandou inicialmente a realização de análise documental em que se pudesse verificar as bases legais e normativas infra legais que orientam a estruturação do ensino para as pessoas com NEE e a formação dos professores para a área. No processo de análise documental foi também relevante consultar autores que investigam as políticas públicas de formação de professores nos dois países. No caso brasileiro tomamos como base os estudos de Kassar (2014) e de Pagnez, Prieto e Sofiato (2015). No caso português pautamo-nos em Rodrigues e Nogueira (2011), Rodrigues e Lima-Rodrigues (2011) e Vidal (2013).

As marcas da globalização das políticas educacionais da área evidenciam-se no desenvolvimento histórico das práticas em educação especial que transitam de processos segregados demarcados pela atuação de instituições filantrópicas até meados da década de 1970, à ênfase nos processos de integração dos alunos no ensino regular que se prolifera nos anos 1980 e o desenvolvimento de processos inclusivos a partir dos anos 2000.

$\mathrm{Na}$ aproximação com o campo de pesquisa em Portugal, percebeu-se como relevante a realização de visitas de observação a escolas do ensino básico onde se desenvolve a atuação dos docentes. Foram selecionados, três agrupamentos de escolas, com base no critério da conveniência, do distrito de Évora: Agrupamento de Escolas n. ${ }^{\circ} 3$ de Évora, Agrupamento de Escolas n. ${ }^{\circ} 4$ de Évora e Agrupamento de Escolas de Monforte. Nestes, além da visita de observação aos espaços onde ocorre a escolarização e o apoio à escolarização dos alunos com NEE, no intuito de conhecer as diferenças e aproximações entre os sistemas de ensino brasileiro e português, realizámos, também, entrevistas com os coordenadores de educação especial, que são os profissionais que mobilizam ações e orientam os demais docentes envolvidos, regentes das classes regulares, com o objetivo de perceber como estes avaliam a formação de professores em Portugal na área de educação especial.

Este processo do contacto com a realidade das ações pedagógicas regulares e específicas desenvolvidas nas escolas deu a oportunidade de ampliar o olhar sobre as necessidades que as práticas docentes podem trazer para a formação dos professores e de que forma se aplica o quadro legal que orienta a referenciação dos alunos como público-alvo da educação especial, considerando o direcionamento para currículos específicos individuais e planos específicos individuais.

Finda esta etapa, realizou-se a análise de planos de ensino e currículos de cursos de instituições de ensino superior (Institutos Politécnicos e Universidades) que fazem a formação de professores em Portugal. No nosso estudo, considerámos 6 instituições formadoras: três Institutos Politécnicos (Beja, Bragança, Lisboa) e três Universidades (Aveiro, Évora, Porto). A seleção das instituições foi por conveniência, considerando em especial a disponibilidade dos seus profissionais em acolher este estudo e os limites técnicos e materiais para a realização da pesquisa.
Foram entrevistados 9 docentes do ensino superior que atuam em disciplinas específicas dos cursos de licenciatura, sendo que, destes, 5 são também coordenadores de cursos de mestrado em educação especial e um coordena um curso de formação de cuidadores de crianças / jovens num Instituto Politécnico.

As entrevistas foram gravadas e transcrito e analisado o seu conteúdo. Revisitaram-se os cadernos de campo e os documentos legais no intuito de construir uma compreensão de como são estabelecidos os processos de formação de professores em Portugal e os seus espaços de aproximação, analisando o distanciamento da realidade brasileira. Pretendia-se fortalecer a reflexão relativa aos caminhos formativos adotados nos dois países e subsidiar a construção de ideias relativas aos que podem vir a possibilidar uma melhor educação das crianças e alunos com NEE.

\section{Resultados}

Entre os principais resultados de nosso percurso de pesquisa, destacamos os diferentes sentidos atribuídos ao conceito de inclusão. Este, como destacam Nunes e Madureira (2015) e Madureira (2016), é um conceito polissémico ao qual podem ser associados diferentes sentidos e consequentemente, diferentes práticas.

No comparativo entre as perspetivas brasileira e portuguesa identificamos um entendimento radicalmente diferenciado do conceito de inclusão que, a grosso modo, assim distinguimos: a realidade brasileira projeta a inclusão como a presença dos estudantes com NEE o mais integralmente possível nas turmas de ensino regular, com uma frágil oferta de serviços que se direcionem às exigências naturais que decorrem da condição biológica dos alunos. No caso português, o entendimento expresso na prática é de que a inclusão só se efetiva na medida em que as NEE individuais, trazidas pela condição biológica dos alunos, forem atendidas.

A constatação central é de que temos um processo em construção que, no Brasil atual, projeta um atendimento aos alunos inseridos nas classes regulares com frágeis estruturas de apoio específico, refletidas, inclusive, na oferta limitada de capacitação profissional, enquanto, em Portugal, a lógica da inclusão toma como pressuposto o fortalecimento dos apoios especializados, traduzidos nos programas educativos individuais. Essa diferenciação nos sentidos de inclusão tem impactos expressivos em três eixos principais que a seguir analisamos.

$\mathrm{Na}$ realidade brasileira, as crianças que apresentam NEE são matriculadas em turmas de ensino regular e aí permanecem nesse turno letivo (matutino ou vespertino), participando de todas as atividades desenvolvidas pela turma, podendo retornar para o serviço de Atendimento Educacional Especializado, em salas de recursos multifuncionais, no turno oposto, 2-3 vezes por semana. Eventuais ajustes necessários para o acesso ao currículo serão da responsabilidade dos docentes titulares da turma, de quem se espera que faça adaptações ou adequações curriculares. Em alguns casos, o aluno conta com o apoio de um cuidador, muitas das vezes, um profissional sem formação especializada. A matrícula do 
aluno é definida a partir da região da sua residência e não com base na sua condição de deficiência.

No caso português, o aluno, alegadamente com NEE, é referenciado para avaliação por qualquer um dos agentes educativos, a saber: encarregado de educação (EE), professor da turma ou diretor de agrupamento. $\mathrm{Na}$ continuação, o aluno é avaliado por uma equipa multidisciplinar no agrupamento onde estuda, composta por professores de educação especial, psicólogo e terapeutas, decidindo-se, em articulação com o EE, as medidas adequadas a adotar. Verificadas as NEE, a equipa constroi um Programa Educativo Individual (PEI), em colaboração com o EE, que define as medidas educativas que o aluno vai beneficiar e os apoios técnicos de que necessita.

Alguns casos de NEE beneficiam de apoios em Unidades de Ensino Estruturado, para alunos com perturbações do espectro do autismo e em Unidades de Apoio Especializado para a Educação a Alunos com Multideficiência. Coexiste, ainda a oferta de escolas de referência para alunos com surdocegueira congénita e outras para alunos com cegueira e baixa visão. É, portanto, a partir da condição de deficiência que se define a matrícula do estudante na escola e não com base na sua residência.

$\mathrm{Na}$ observação realizada nas escolas e com base nas entrevistas aos professores coordenadores de educação especial, destaca-se o facto de que os alunos com deficiência passarem parte expressiva de sua carga horária nas Unidades de Apoio ou de Ensino Estruturado, aos cuidados de professores especializados em educação especial e o facto de que, em alguns casos, alunos com maiores comprometimentos cognitivos acabarem por permanecer em todo o período letivo, nestas salas, com raras oportunidades de participação com os demais colegas.

Como afirma uma das entrevistadas:

Nos nossos trabalhos de investigação, que são orientados por nós, elaborados nos cursos de Mestrado, demo-nos conta que muitos alunos estão nas escolas naquilo que se chama de unidades de ensino estruturado. Podem ser unidades de ensino estruturado para multideficiência ou unidades de apoio aos alunos do espectro do autismo. Nós vimos que eles estão pouco tempo dentro das suas classes e muito tempo nas unidades $(16 \%$ do tempo na classe regular e todo o outro tempo nas unidades). E vão no primeiro ciclo do ensino básico [com alunos de 6-10 anos de idade], em momentos que as professoras considerem que não vão perturbar a sala. No segundo [10-12 anos] e terceiro ciclos [12-15 anos] do ensino básico eles acompanham os seus colegas em educação física e em educação visual ou tecnológica. Nas ditas disciplinas nobres (português, matemática, história, ciências) muito pouco estão dentro da sala. No primeiro ciclo, nós temos, portanto, uma diferenciação entre os alunos.

Confrontados com a justificativa para que os estudantes realizem apenas algumas atividades com estudantes sem NEE, a motivação é atribuída ao entendimento de que a inclusão só pode efetivar-se se os alunos tiverem as suas NEE atendidas. Essa uma das distinções mais expressivas na comparação com a realidade brasileira. $\mathrm{O}$ acesso a serviços especializados que venham a dar conta das NEE dos alunos é bastante limitado, permanecendo em contato direto com os demais alunos, em todas as aulas, mesmo nos casos em que pouco ou nenhum acesso ao currículo se efetive, ou sem que a interação entre os alunos com e sem NEE ocorra.

Nas perspectivas de escolarização dos alunos com NEE dos dois países, o desafio central é o de que a mesma ocorra nas escolas de ensino regular. Como já foi apontado, existe uma diferenciação expressiva no volume e qualidade de apoios específicos oferecidos aos alunos.

Um aspecto que aproxima os processos educativos desenvolvidos nos dois países é a manifesta expectativa dos professores das disciplinas e turmas de ensino regular de que os estudantes público-alvo da educação especial sejam de responsabilidade dos profissionais especializados.

Neste sentido, é sobre o profissional especializado que recaem as expectativas de atendimento às necessidades de ensino e aprendizagem dos alunos, havendo um reincidente discurso quanto ao sentido de não pertencimento do alunos aquele ambiente e o discurso do "despreparo" apresentado pelos docentes regentes do ensino regular nos dois países. Assiste-se, por assim dizer, mais a uma tolerância da presença do que a uma integração propriamente dita.

Individualizados através dos PEI, constituem-se no diferencial mais expressivo no processo de escolarização dos alunos com NEE na realidade portuguesa, em contraponto às práticas brasileiras, que não privilegiam a formação por área, e estabelecem como aspecto chave a considerar na alocação de alunos nas escolas a proximidade da morada deste.

Em Portugal, a formação em educação especial, ao nível de mestrado é por áreas de domínio. Além disso, existe o caso de professores, já com experiência de 5 anos em qualquer área de docência no ensino regular, que, mesmo sem a realização do estágio ser certificado como especialização, e sem ter qualquer contacto formal orientado com alunos na condição de deficiência, são titulados como "especialistas". Tal facto parece-nos configurar uma fragilidade expressiva, se considerarmos a multiplicidade de perfis que podem manifestar-se entre os alunos concretos que necessitam ser atendidos nos contextos educativos, fazendo com que, em muitos casos tenham que deslocar-se para regiões distantes de sua área de residência para o acesso ao ensino especializado. A capacitação docente para a educação especial deveria incluir, no nosso ponto de vista, práticas supervisionadas por professores de educação especial séniores. A prática é o campo de aplicação da teoria; deixar a especialização no campo da sala de aula surge-nos como uma perspetiva claramente redutora do desenvolvimento profissional dos professores e da capacidade de intervenção junto dos alunos com NEE.

Em contraponto, na perspectiva brasileira, atendendo ao normativo legal, as matrículas dos alunos com NEE tendem a dar-se nas proximidades da residência dos alunos e, portanto, em área próxima ao seu grupo social de pertença. A formação oferecida aos professores brasileiros, mesmo quando especializada, tem um enfoque generalista, com menor aprofundamento por 
área, mas com a possibilidade de basear-se em iniciativas de atuação junto a estes alunos, independentemente da sua condição específica identificada como base na condição humana presente em todos.

Nos dois casos, a expectativa é no sentido de que o profissional especializado seja o profissional que atenderá a todas as NEE dos alunos. O sentido de "não-responsabilização" dos docentes do ensino regular, pelas necessidades dos alunos aproxima os profissionais dos dois países. Um aspecto que destacamos é o facto de na realidade portuguesa o processo de referenciação dos alunos contar com a participação e escuta dos docentes do ensino regular, que também partilham dos processos de construção da planificação do percurso que será desenvolvido pelo aluno individualmente. No caso brasileiro, a participação dos docentes no processo de diagnóstico, embora conste em normativos legais, não é uma prática comum, recaindo sobre os profissionais da área clínica a expectativa de que estabeleçam um laudo que, de maneira geral, traz pouca ou nenhuma informação que subsidie a adoção de medidas no processo de construção do percurso pedagógico dos estudantes

\section{Considerações finais}

Trazer a educação das pessoas público-alvo da educação especial para um contexto de escolarização e que envolva a participação social é um desafio às políticas educacionais em âmbito mundial. No caso dos países que tomamos como base de nossa pesquisa, Portugal e Brasil, este desafio vem sendo enfrentado com estratégias bastante diferenciadas e que nos encaminham para um rico processo de reflexão sobre possibilidades de enfrentamento deste desafio.

Em Portugal, o eixo central das ações emerge, em nosso entendimento, do olhar focado no compromisso em atender as necessidades trazidas pelas diferentes condições biológicas através da oferta de atendimentos o mais especializados possíveis. No Brasil, o investimento maior vem sendo feito no olhar sobre um sujeito global, multifacetado, com maior ênfase aos pontos de aproximação entre os diferentes sujeitos, com investimento menor no atendimento às necessidades específicas.

Estes diferentes sentidos são confirmados em discursos de docentes entrevistados que, chamados a refletir sobre qual seria sua perspectiva melhorada na formação de professores assim se posicionam: "eu ensinaria aos meus alunos a trabalhar com as crianças na escola em termos de observar, avaliar, elaborar relatórios e desenhar formas de intervenção, programas de intervenção para cada criança”.

Outra coordenadora de formação em nível de mestrado, instigada a manifestar-se acerca do projeto de formação desejado, propõe que a formação de professores da educação especial se atente mais à gestão do currículo e de desenvolvimento de estratégias que favoreçam a interlocução entre todos os profissionais que contribuem para a escolarização dos alunos, do que para o estudo de particularidades da condição biológica ou de metodologias de ensino que partem das limitações de natureza biológica dos estudantes.

Diferentes percursos, diversos entendimentos, que se encontram no propósito definido de construir caminhos educacionais que rompam com a naturalização da exclusão da significativa população de estudantes com necessidades educativas especiais.

\section{Referências bibliográficas}

Costa, A. (2008). Deliberação da secção formação especializada sobre a acreditação de cursos na área de educação especial. Disponível em: http://www.ccpfc.uminho.pt/uploads/Delibera\%C3\%A7 $\%$ C3\%A3o\%20FE.pdf.

Kassar, M. (2014). A formação de professores para a educação inclusiva e os possíveis impactos na escolarização de alunos com deficiências. Cadernos CEDES 34(93), 207-224. Disponível em: http://www.scielo.br/pdf/ccedes/v34n93/0101-3262-cced es-34-93-0207.pdf.

Madureira, I. (2016). Pedagogia Inclusiva- Princípios e práticas. In Borges, M., Luísa, C., \& Martins, M. (Coords.), II Congresso Internacional de Direitos Humanos e Escola Inclusiva: Múltiplos Olhares (pp. 4251). Faro: Universidade do Algarve. Disponível em: https://sapientia.ualg.pt/bitstream/10400.1/8999/6/e-book \%20final\%2017-05-2017.pdf.

Nunes, C., \& Madureira, I. (2015). Desenho universal para a aprendizagem: Construindo práticas pedagógicas inclusivas. Da investigação às práticas, 5(2), 126-143. Disponível

em: http://www.scielo.mec.pt/scielo.php?script=sci_arttext\&p id $=$ S2182-13722015000200008\&lng=pt\&tlng=pt.

Pagnez, K., Prieto, R., \& Sofiato, C. (2015). Formação de Professores e Educação Especial: reflexões e possibilidades. Olh@res, 3(1), 32-57. Disponível em: http://www.olhares.unifesp.br/index.php/olhares/article/v iew/320/121.

Rodrigues, D., \& Lima-Rodrigues, L. (2011). Formação de Professores e Inclusão: como se reformam os reformadores. Educar em Revista, 41, 41-60. Disponível em: http://www.scielo.br/pdf/er/n41/04.pdf.

Rodrigues, D., \& Nogueira, J. (2011). Educação Especial e Inclusiva em Portugal: fatos e opções. Revista Brasileira de Educação Especial, 17(1), 3-20. Disponível em: http://www.scielo.br/pdf/rbee/v17n1/v17n1a02.pdf.

Vidal, M. (2013). O processo de Bolonha e as políticas de formação inicial com vistas à educação inclusiva. Tese Doutoramento (não publicada). Uberlândia, MG: Universidade Federal de Uberlândia. Disponível em: https://repositorio.ufu.br/bitstream/123456789/13639/1/ MARIAHELENA.pdf.

\section{Agradecimentos}

Os autores agradecem aos diretores de agrupamentos de escolas e aos respetivos docentes que acederam colaborar neste estudo, bem como aos docentes das instituições de ensino superior que aceitaram receber-nos para discussão.

Este trabalho foi financiado pelo Programa de Bolsas Ibero-Americanas para Jovens Professores e Pesquisadores Santander Universidades 2015 para a realização de um estágio na Universidade de Évora. 